\title{
Advances in nanomaterials for use in photothermal and photodynamic therapeutics (Review)
}

\author{
ZHIZHOU YANG $^{1 *}$, ZHAORUI SUN $^{1 *}$, YI REN $^{1}$, XIN CHEN $^{1}$, WEI ZHANG $^{1}$, \\ XUHUI ZHU ${ }^{1,2}$, ZONGWAN MAO ${ }^{3}$, JIANLIANG SHEN ${ }^{4,5}$ and SHINAN NIE ${ }^{1}$ \\ ${ }^{1}$ Department of Emergency Medicine, Jinling Hospital, Medical School of Nanjing University; ${ }^{2}$ Department of \\ Epidemiology and Microbiology, Huadong Medical Institute of Biotechniques, Nanjing, Jiangsu 210002; \\ ${ }^{3}$ MOE Key Laboratory of Bioinorganic and Synthetic Chemistry, School of Chemistry, Sun Yat-sen University, \\ Guangzhou, Guangdong 510275; ${ }^{4}$ State Key Laboratory of Ophthalmology, Optometry and Vision Science, \\ Wenzhou Medical University, Wenzhou, Zhejiang 325035; ${ }^{5}$ Wenzhou Institute of Biomaterials and Engineering, \\ Chinese Academy of Science, Wenzhou, Zhejiang 325001, P.R. China
}

Received March 21, 2018; Accepted October 23, 2018

DOI: $10.3892 / \mathrm{mmr} .2019 .10218$

\begin{abstract}
Nanomaterials play crucial roles in the diagnosis and treatment of diseases. Photothermal and photodynamic therapy, as two minimally invasive therapeutic methods, have promising potential in the diagnosis and prevention of cancer. Recently, many photothermal materials (such as noble metal material, transition metal sulfur oxides, carbon material and upconversion nanomaterial) and photodynamic materials (such as phthalein cyanogen, porphyrins and other dye molecules) have been applied in photothermal therapy (PTT) and photodynamic therapy (PDT). Moreover, as nanomaterials have suitable biocompatibility, these materials have been applied in cancer therapy. In the present review, we summarized the effects of different material types, synthesis methods, material morphologies and surface modifications on the outcomes of cancer therapy. The application of nanomaterials in PTT and PDT was introduced and the advantages and disadvantages of PTT and PDT in the prevention of cancer were discussed. Finally, we discussed the application of nanomaterials in the combination of PTT and PDT in cancer treatment.
\end{abstract}

Correspondence to: Dr Shinan Nie, Department of Emergency Medicine, Jinling Hospital, Medical School of Nanjing University, 305 East Zhongshan Road, Nanjing, Jiangsu 210002, P.R. China E-mail:shn_nie@sina.com

${ }^{*}$ Contributed equally

Key words: nanomaterial, cancer, photothermal therapy, photodynamic therapy

\section{Contents}

1. Introduction

2. Application of nanometer materials in PTT

3. Application of nanometer materials in PDT

4. Combination of PTT and PDT

5. Conclusions

\section{Introduction}

Cancer is the second leading cause of human mortality. In phototherapy, specific wavelengths of light are adopted to treat diseases including both cancer and infection (1-4). To date, photothermal therapy (PTT) and photodynamic therapy (PDT) are the two most common phototherapy methods for treating cancer (5). In PTT, a photothermal (PT) agent is stimulated by both specific band light and vibrational energy/heat release to selectively target abnormal tissues and cells (6). In PDT, photosensitizer (PS) drugs which are photoactivated molecules or materials, generate reactive oxygen species (ROS) through a series of photochemical reactions. As a result, the triggered oxidative stress in target cells is able to induce intracellular lipid peroxidation, DNA injury and protein damage, ultimately leading to cell death $(7,8)$. Recently, nanomaterials have garnered much attention and have been extensively studied (9-11). Many effective photothermal and photodynamic nanomaterials have been applied in the diagnosis and treatment of cancer $(12,13)$. The discrepancies, for example, size, structure and morphology, existing between PTT and PDT materials may affect the effectiveness of phototherapy. This review predominantly summarizes the effects produced by different types, formulations, morphologies and modifications on the photothermal or photodynamic properties of materials. Moreover, we compared the effectiveness of distinct nanomaterials in cancer phototherapy and discussed the advantages and disadvantages of PTT and PDT. In addition, we introduce the application of the assembly of 
nanomaterials in cancer phototherapy. Thus, the present study aimed to i) summarize PT and PD materials, ii) present their properties and iii) discuss their relevance in cancer therapy.

\section{Application of nanometer materials in PTT}

Precious metal nanomaterials. Recently, Au (gold) nanocages, a novel class of nanomaterials, have been reported to be potential photothermal transducers and drug carriers for mainstream clinical practice in the near future (14). Au nanocages have attracted great attention in regards to cancer imaging, diagnosis and treatment $(15,16)$. Wang et al $(17,18)$ and Shrestha et al (19) showed that Au nanostructures were able to absorb near infrared light and convert light to heat. Among Au nanorods, Au nanocages and Au nanohexapods, the effect of Au nanohexapods was found to be highly outstanding and it exhibited the highest cell uptake and the lowest cytotoxicity in vitro (18). Moreover, in athymic mice (Nude-Foxn1nu nude) bearing breast tumors (the tumors were generated through an subcutaneous injection of MDA-MB-435 cells in the right flanks of mice), the PEGylated Au nanohexapods displayed significant blood circulation. Additionally, this study also showed that the accumulation of nanoparticles (passive target effect) in the tumor site was elevated due to the enhanced penetration effect of the nanoparticles (18). Thus, heat was produced to dampen target cancer cells in PTT based on the PEGylated Au nanostructures (18). These results indicated the biocompatibility of the Au nanostructures in vivo, pointing to the potential application of Au nanostructures in the clinic. Furthermore, the temperature around the tumor region was higher in the PEGylated Au nanohexapods than temperatures in other PEGylated Au nanostructures (Fig. 1A and B). In this way, the tumors absorbed more heat through the PEGylated Au nanohexapods, therefore helping realize the goal of detecting and treating the cancer. Researchers have reported that as a new class of branched Au nanostructures, Au nanohexapods are more effective in drug loading and photothermal conversion in comparison to those with smoother surfaces $(20,21)$. Therefore, we conclude that Au nanohexapods are a promising candidate material for the diagnosis and treatment of cancer.

Transition metal sulfide materials. Although precious metal nanomaterials have attracted much attention in PTT due to their strong absorption of near infrared light (22), transition metal sulfide materials that have the effect of surface plasma resonance are gaining increased attention for their advantages of low-price, high efficiency of photothermal conversion and competent biocompatibility $(23,24)$. One study reported that copper sulfide $(\mathrm{CuS})$ nanoparticle-based drug delivery was effective in cancer treatment (25). In this study, the $\mathrm{CuS}$-based drug was not only taken up by MCF-7 cells and could effectively convert NIR light into heat, but also generated a large amount of reactive oxygen species (ROS) for photodynamic therapy. Moreover, the photothermal heating of $\mathrm{Cu}_{2-x} \mathrm{Se}$ nanocrystals after $5 \mathrm{~min}$ of laser irradiation at $33 \mathrm{~W} / \mathrm{cm}^{2}$ led to the cell destruction of human colorectal cancer HCT-116 cells, pointing to the possible viability of $\mathrm{Cu}_{2-\mathrm{x}} \mathrm{Se}$ for PTT therapy (26). Furthermore, tungsten oxide has also been confirmed to be pertinent to tumor CT imaging and PTT (27).
The effect of $\mathrm{W}_{18} \mathrm{O}_{49}$ nanowire in PTT has been explored in a previous study (28). The results of the study showed that ultrathin PEGylated $\mathrm{W}_{18} \mathrm{O}_{49}$ nanowire was formulated by heating $\mathrm{WCl}_{6}$ with ethanol and PEG. Following this treatment method, the prepared blue aqueous dispersions with $\mathrm{W}_{18} \mathrm{O}_{49}$ nanowires were able to enhance the absorption of near infrared light. Under the irradiation of a 980-nm laser (which is safe for humans when the power density is set to $\left.0.72 \mathrm{~W} \cdot \mathrm{cm}^{2}\right)$, the temperature of aqueous dispersions with the $\mathrm{W}_{18} \mathrm{O}_{49}$ nanowires $(0.25-3.0 \mathrm{~g} / \mathrm{l})$ was increased by $12.2-41.2^{\circ} \mathrm{C}$ within $5 \mathrm{~min}$ (28). In the animal studies, severe combined immunodeficiency (SCID) mice were inoculated with K7M2 cells and were grouped into control and treatment groups. Mice in the treatment group were injected with $\mathrm{W}_{18} \mathrm{O}_{49}$ nanowires $(100 \mu \mathrm{l}, 2 \mathrm{~g} / \mathrm{l})$ at the central region of the tumor with a depth of $\sim 4 \mathrm{~mm}$. Mice in the control and treatment groups were simultaneously irradiated for $10 \mathrm{~min}$ at $0.72 \mathrm{~W} / \mathrm{cm}^{2}$ by two similar $980-\mathrm{nm}$ laser devices. Full-body thermographic images and temperature were recorded during the irradiation. It was observed that the temperature of tumor tissues was quickly elevated to $50.0 \pm 0.5^{\circ} \mathrm{C}$ within $120 \mathrm{sec}$ of irradiation (28) (Fig. 2). Hence, as a near-infrared laser-induced photothermal agent, the PEGylated $\mathrm{W}_{18} \mathrm{O}_{49}$ nanowires exhibited superior efficiency in PTT and such an efficacy can be largely explained by their high efficiency of photothermal conversion and low cytotoxicity.

The influencing factors in PTT. The morphology of a nanomaterial has significant effects on its physical chemistry and biological properties (29). The flower-like nano copper sulphide can be prepared by the hydrothermal method as previously described (30). The light can be reflected in nano-flowered copper sulphide multiple times based on the mechanism of light reflection (Fig. 3A). As a result, the photoabsorption is increased and the photothermal conversion efficiency is enhanced. Researchers have confirmed that the photothermal conversion efficiency of flower-like nano copper sulphide is elevated by $50 \%$ in comparison to ordinary hexagonal sulfide nanoparticles (30). In addition, the temperature of a superstructure nano- $\mathrm{CuS}$ aqueous solution was found to be increased by $17.3^{\circ} \mathrm{C}$ within 5 min under irradiation with a low power density of $0.51 \mathrm{~W} \cdot \mathrm{cm}^{2}$ by a $980-\mathrm{nm}$ laser in vitro (Fig. 3B). These findings may inspire researchers to develop nanoparticles that can provide high photothermal conversion efficiency in PTT.

As reported by Tian et al (31), the photothermal conversion efficiency of $\mathrm{Cu}_{9} \mathrm{~S}_{5}$ nanoparticles reached $25.7 \%$, which was higher than that of as-synthesized Au nanorods (23.7\% from $980 \mathrm{~nm}$ laser) and that of $\left(\mathrm{Cu}_{2 x} \mathrm{Se}\right)$ nanocrystals (NCs) $(22 \%$ from an 808-nm laser). The temperature of $\mathrm{Cu}_{9} \mathrm{~S}_{5} \mathrm{NCs}(40 \mathrm{ppm})$ reached $15.1^{\circ} \mathrm{C}$ within 7 min under the irradiation condition of a $980-\mathrm{nm}$ laser with a power density of $0.51 \mathrm{~W} \cdot \mathrm{cm}^{2}$. Moreover, although semiconductor nanocrystals containing copper exhibit low cost and low toxicity, they have a high stability and high photothermal conversion efficiency (32). Importantly, the cancer cells can be killed by the photothermal effects of the $\mathrm{Cu}_{9} \mathrm{~S}_{5} \mathrm{NCs}$ under 980-nm laser irradiation with the conservative and safe power density over a short period ( 10 $\mathrm{min})(31)$. A previous study demonstrated that the DNA-decorated $\mathrm{Cu}_{9} \mathrm{~S}_{5}$ nanoparticles could be used as NIR light responsive drug carriers in tumor chemo-phototherapy (33). This indicated that 


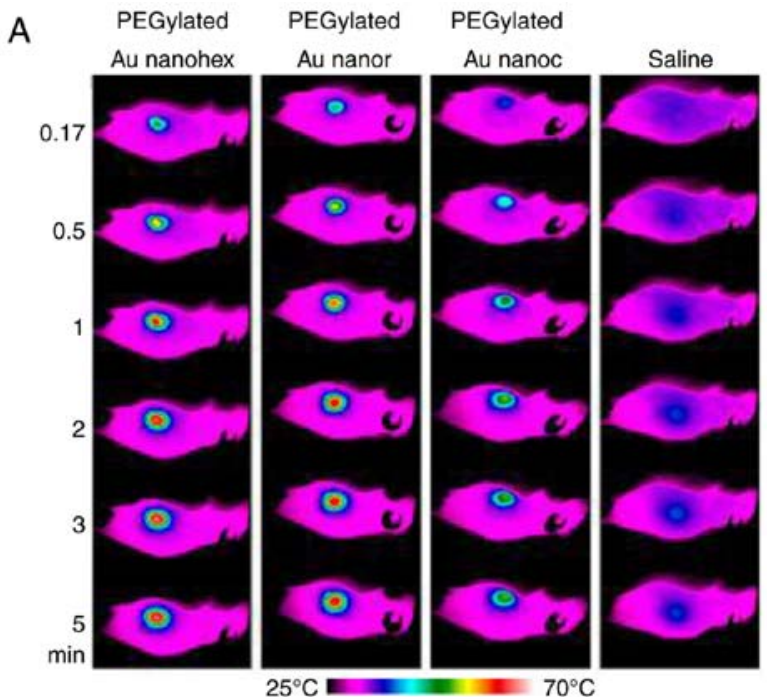

B

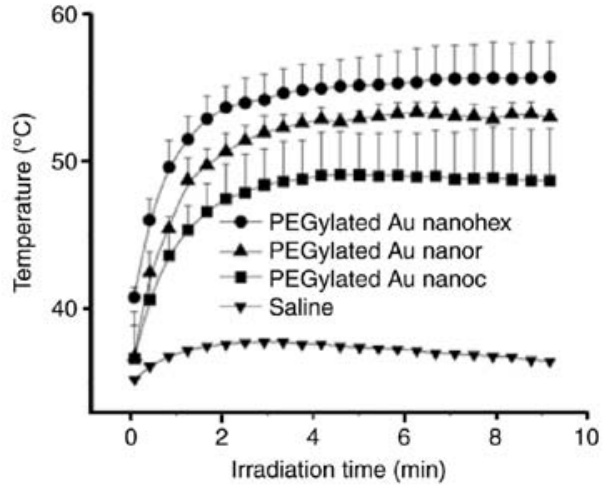

Figure 1. (A) Thermographs indicating the temperature of tumor tissues in mice for different periods of time in PTT. The mice were intravenously injected with aqueous suspensions of PEGylated nanohexapods, nanorods, nanocages and saline. (B) The relation of average temperature within the tumor tissues and the irradiation time. Laser power density, $1.2 \mathrm{~W} \cdot \mathrm{cm}^{2}$ (Reprinted from ref 18 with permission. Copyright 2013, American Chemical Society). PTT, photothermal therapy; nanohex, nanohexapods; nanor, nanorods; nanoc, nanocages.

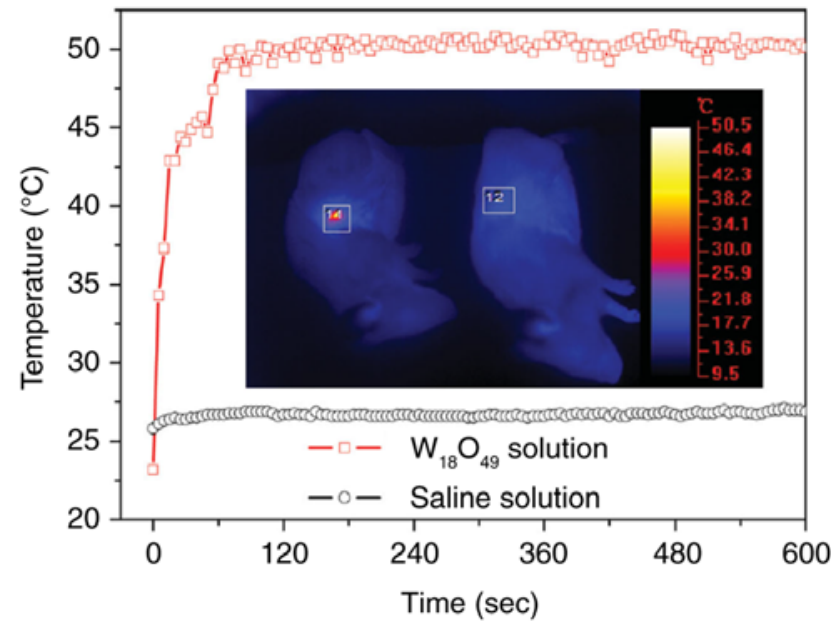

Figure 2. Temperature of PEGylated $\mathrm{W}_{18} \mathrm{O}_{49}$ nanowire in vivo and in vitro. Laser, $980 \mathrm{~nm}$; power density, $0.72 \mathrm{~W} \cdot \mathrm{cm}^{2}$. The concentration of $\mathrm{W}_{18} \mathrm{O}_{49}$ nanowire PBS solution was $2 \mathrm{~g} / 1$ (Reprinted from ref 28 with permission. Copyright 2013, John Wiley and Sons).

the efficient photothermal effects produced by nanoparticles may contribute to killing cancer cells.

Thermal stability is a highly critical parameter for photothermal materials (34). If the heating rate far exceeds the cooling rate, the heat will rapidly accumulate in the lattice. Therefore, a high temperature of nanoparticles will be reached at a specific area over a short period of time, and structural changes in terms of the shape or integrity of nanoparticles will result (35). A previous study showed that core-shell nanomaterial- $\mathrm{Fe}_{3} \mathrm{O}_{4} @ \mathrm{Cu}_{2-\mathrm{x}} \mathrm{S}$ has high photothermal stability and super-paramagnetism (36). This previous study also confirmed that as they had an intense absorption in the near infrared region of $960 \mathrm{~nm}$, these core-shell nanomaterials could serve as a magnetic resonance imaging $\mathrm{T} 2$ contrast agent and were able to be employed in infrared thermal imaging. Furthermore, the photothermal effect of nanoparticles can be controlled by altering the content of $\mathrm{Cu}$ in the core-shell nanomaterials. The synergistic effect of magnetic and photothermal phenomena employed in this study may lay a solid foundation for the development of nanoprobes in multimode biomedicine application. In addition, the thermal stability of core-shell nanomaterials was also improved in the same study. From the transmission electron microscope laser scanning images, it was clearly observed that the shape of core-shell nanomaterials and the absorption of near infrared remained approximately the same after administration of 980-nm laser irradiation for $30 \mathrm{~min}$ (Fig. 4). This suggested that the thermal stability of nanomaterials is critical in biomedical application.

Carbon nanomaterials. Carbon nanotubes are able to absorb near-infrared light so as to efficiently convert light to heat (37). Thus, carbon nanotubes could be used for thermal ablation, diagnosis and drug delivery in cancer for its high aspect ratio, ultra-light weight, high mechanical strength, high electrical conductivity and high thermal conductivity (38). Ultra-small nano-reduced graphene has been demonstrated to possess acceptable performance in absorbing near-infrared light (39). The size and surface compositions of graphene are in close relation to its thermal properties (40). The average transverse dimension of graphene is approximately $20 \mathrm{~nm}$. The modification with targeted peptides can increase the specificity of graphene in killing target cells (41). As demonstrated by Yang et al (40), the damage to cancer cells was dramatically augmented in raphene-based PTT. Nevertheless, the power density of the laser used in this study was $0.15 \mathrm{~W} \cdot \mathrm{cm}^{2}$, which is less than the power density used $\left(0.5-2 \mathrm{~W} \cdot \mathrm{cm}^{2}\right)$ by most photothermal research institutes.

Liu et al (42) developed graphene-iron oxide-gold nanoparticles (GO-IONP-Au), which efficiently combined the photothermal properties of graphene (the magnetic properties of iron oxide) and the properties of the surface plasma resonance of gold nanoparticles. Moreover, the 

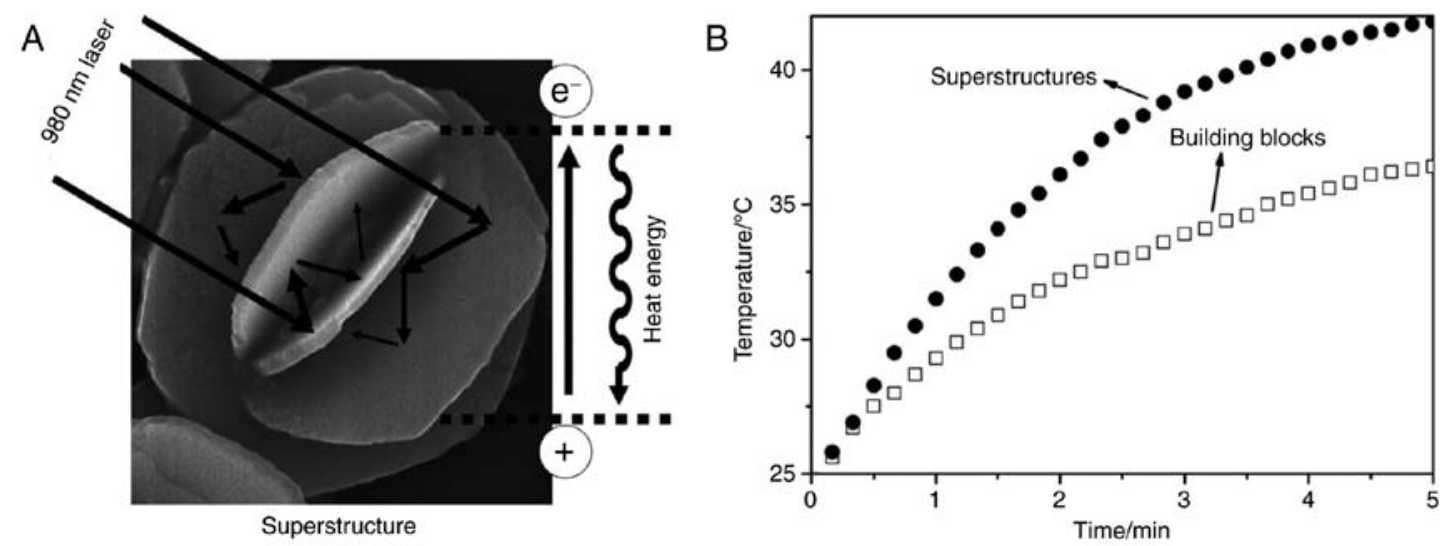

Figure 3. (A) Schematic diagram for mirror and photothermal transformation of superstructure nanoCuS. (B) The relation between temperature and superstructure nanoCuS for different periods of time. Laser, $980 \mathrm{~nm}$; power density, $0.51 \mathrm{~W} \cdot \mathrm{cm}^{2}$ (Reprinted from ref 30 with permission. Copyright 2011, John Wiley and Sons).

A

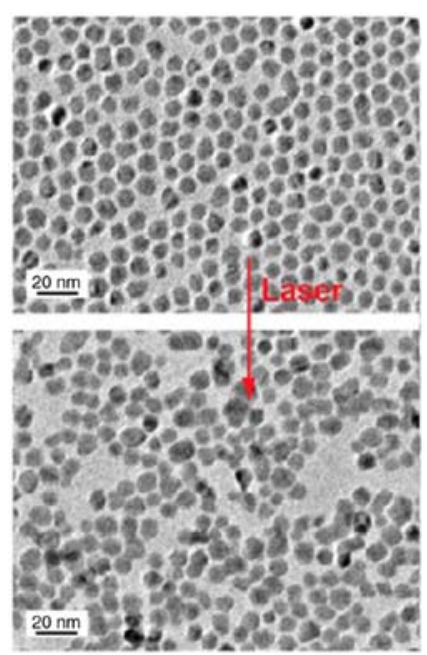

C
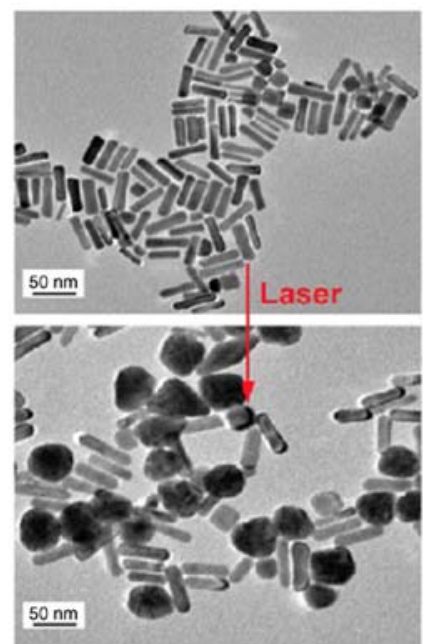

B

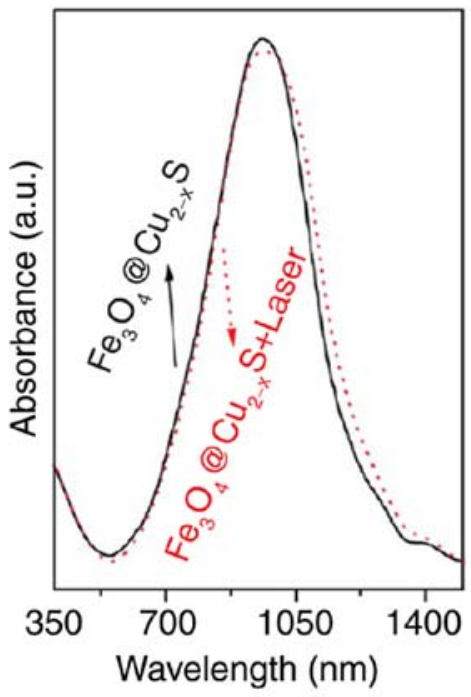

D

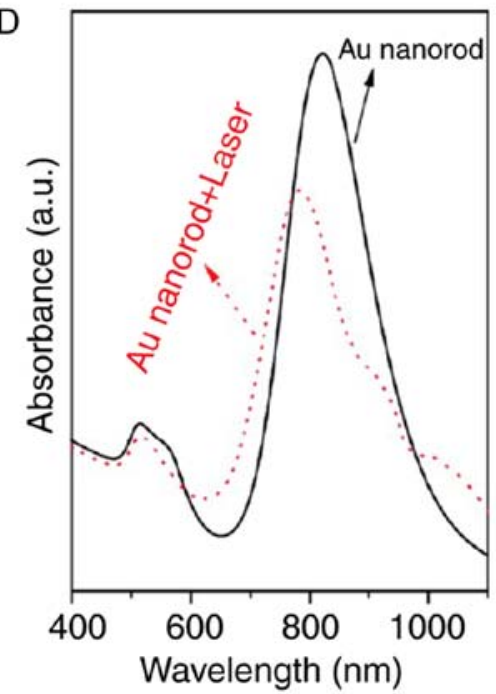

Figure 4. Photothermal stability comparison for (A and B) $\mathrm{Fe}_{3} \mathrm{O}_{4} @ \mathrm{Cu}_{2-\mathrm{x}} \mathrm{S}$ core-shell nanomaterials and (C and D) Au nanorods (50x15 nm). Laser, $980 \mathrm{~nm}$; power density, $2 \mathrm{~W} \cdot \mathrm{cm}^{2}$; irradiation time, 30 min (Reprinted from ref 36 with permission. Copyright 2013, American Chemical Society).

folate receptor on GO-IONP-Au nanoparticles showed better performances in target cell killing and damage. Thus,
GO-IONP-Au acquired both passive and active targeting prosperities. Moreover, GO-IONP-Au has magnetic properties 

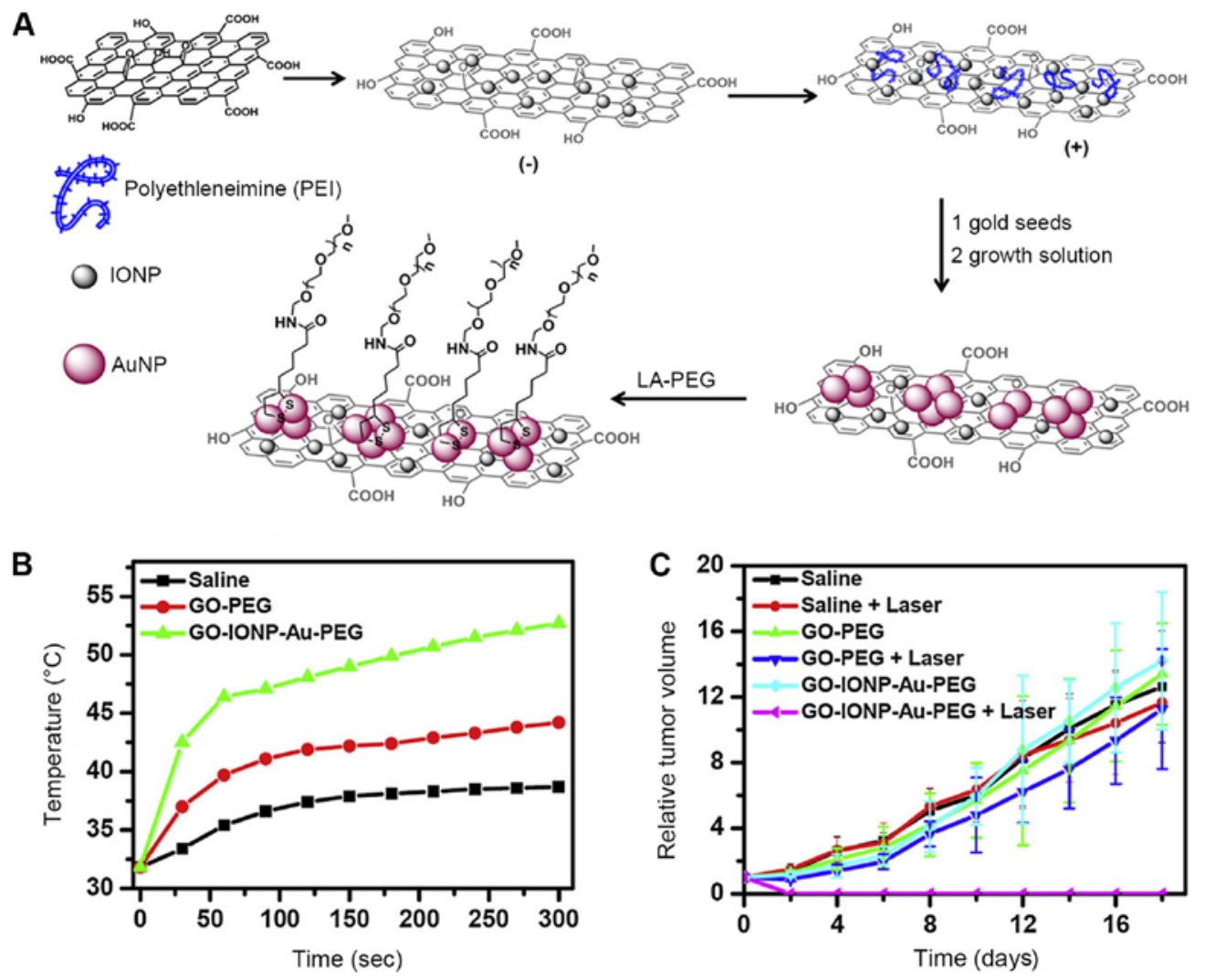

Figure 5. (A) The formulation of PEGylated GO-IONP-Au. (B) The temperature for different periods of time in GO-PEG, GO-IONP-Au-PEG and saline. (C) The tumor growth curves of tumor-bearing mice in different periods of time (Reprinted from ref. 74 with permission. Copyright 2013, Elsevier Ltd. All rights reserved).

and thus could be employed as an imaging agent for nuclear magnetic imaging in cancer therapy. Additionally, the surface plasma resonance effect produced by gold nanoparticles in GO-IONP-Au increased its photoabsorbtion and light-heat conversion efficiency. As an effective PTT agent, graphene in combination with gold nanoparticles also enhanced the effect of GO-IONP-Au in PTT. Furthermore, Liu et al also proved that PEG modifications enabled the GO-IONP-Au to be more biocompatible. GO-IONP-Au inhibited tumor growth and reduced the tumor size in vivo (Fig. 5). In summary, as graphene-based photothermal nanocomposites, GO-IONP-Au is a powerful and promising PTT agent that can be applied in dual mode imaging (nuclear magnetic imaging and thermal imaging) with its multi-functional magnetic, surface plasma resonant effects. This suggested that graphene-based multi-functional nanocomposite materials have great potential in the diagnosis and treatment of cancer.

For its suitable biocompatibility, the effect of PEG-BPEI-rGO nanocomposites in gene transfection has already been investigated (43). In this previous study, the collapse of the endocytosis containing the transfection gene was regulated by heat, thereby controlling the time and site of gene release. This not only provided a simple, practical and highly efficient strategy for developing possible drugs and gene carriers, but also inspired a new insight for gene therapy.

\section{Application of nanometer materials in PDT}

Combining photosensitizers and light irradiation, photodynamic therapy (PDT) is an emerging new treatment
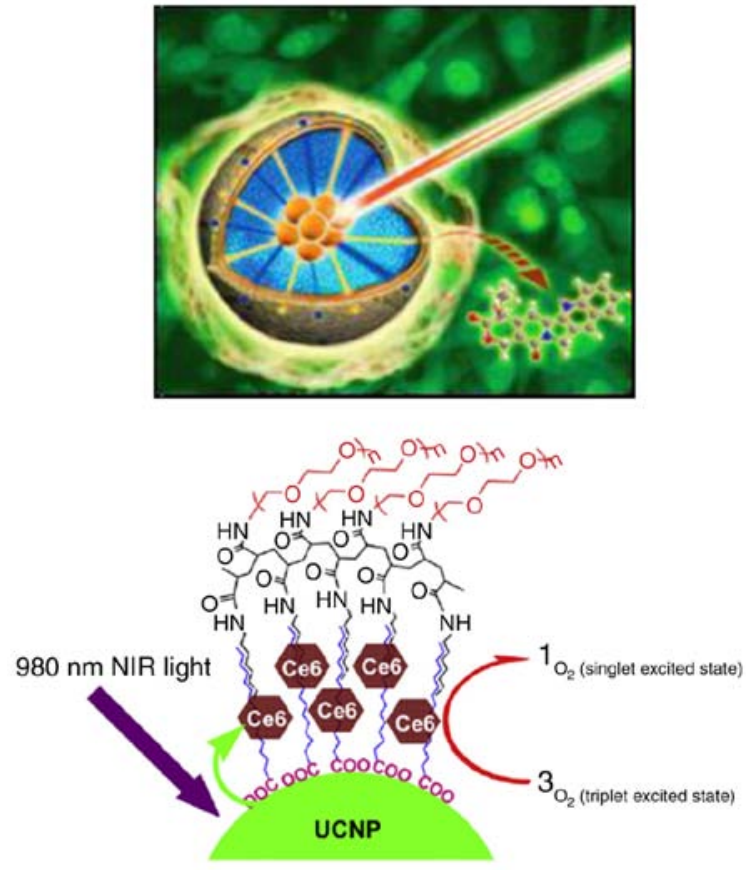

Figure 6. Schematic diagram for the application of upconversion nanoparticles in PDT (Reprinted from ref 7 with permission. Copyright 2011, Elsevier Ltd. All rights reserved). PDT, photodynamic therapy; NIR, near-infrared light; UCNP, up-converting nanophosphors.

method for treating various diseases, including cancers (such as lung, breast, bladder and brain cancer) and non-cancer diseases (such as bacterial and fungal infections, premalignant 
A

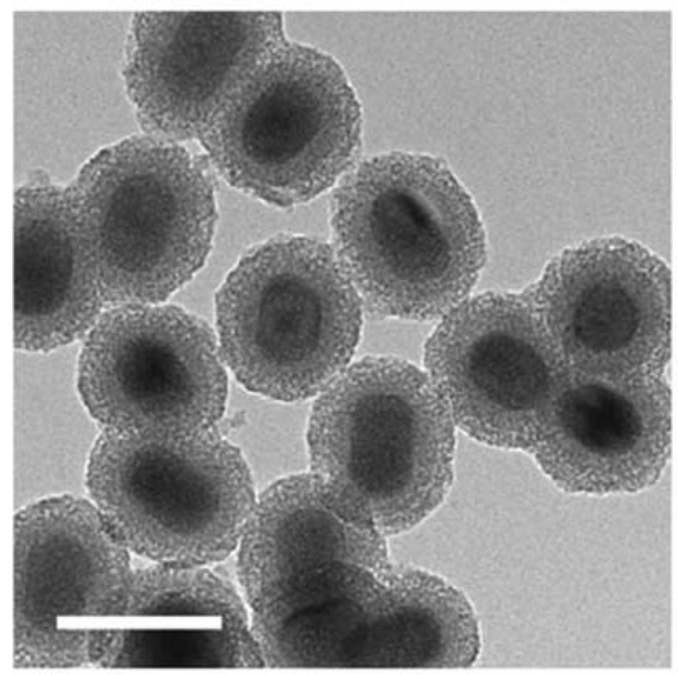

C

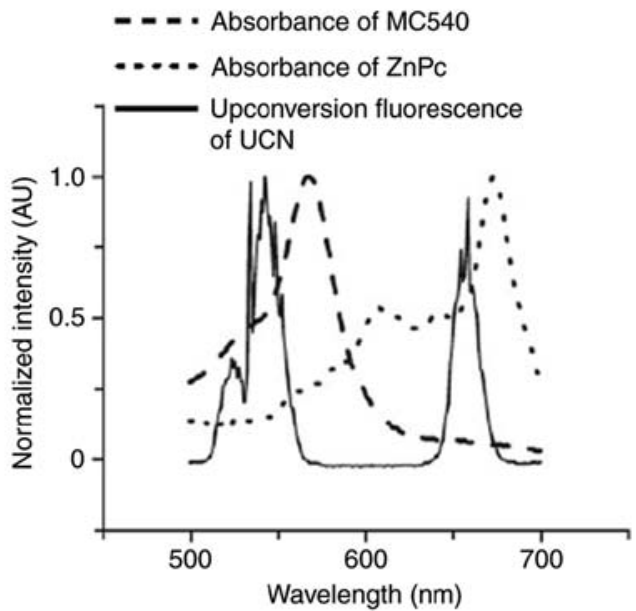

B

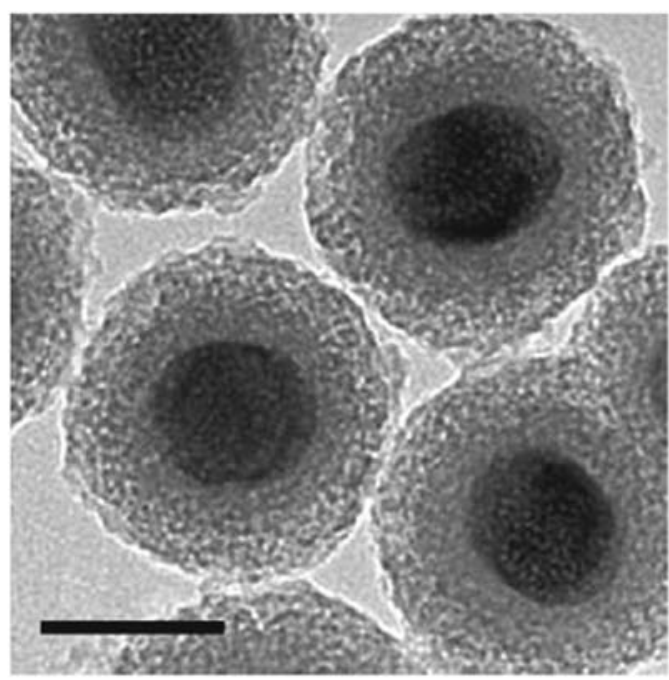

D Mesoporous silica layer encapsulating
$\mathrm{ZnPc}(\bullet)$ and $\mathrm{MC5} 40$ (०) photosensitizers

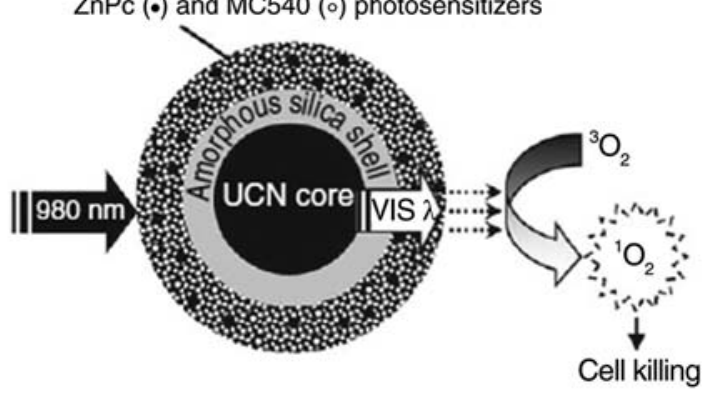

Figure 7. (A and B) Scanning electron microscopy (SEM) images of $\mathrm{NaYF}_{4}: \mathrm{Yb} /$ Er upconversion nanoparticles coated with mesoporous-silica. (C) Photoluminescence spectroscopy of MC540, ZnPc and upconversion fluorescence of UCN (dashed lines indicate the curve of photosensitizer light absorption). (D) The treatment mechanism of MC540 and ZnPc (Reprinted from ref 53 with permission. Copyright 2012, Springer Nature). UCN, upconversion nanomaterials.

conditions and inflammatory conditions) (44). Nevertheless, most of the conventional PDT photosensitizers are stimulated by visible light (VIS), which cannot penetrate thick tissues or reach deep tumor tissue (45). Thus, VIS can only be employed in treating skin or shallow tissues. A range of $700-1,100 \mathrm{~nm}(8,46)$ has been accepted as the absorption window for most biomolecules. Therefore, near-infrared light (NIR) was adopted in PDT as NIR can penetrate deep tissue, eliminating cancer cells.

Upconversion nanoparticles. Upconversion nanoparticles are able to convert light from long wavelengths to short wavelengths through the excitation of NIR light (47). Upconversion nanoparticles with fine crystallinity and monodispersity have been successfully synthesized, with their sizes controlled within $100 \mathrm{~nm}$ (48). A previous study reported that penetrated NIR light is converted into VIS by upconversion nanoparticles in a diseased site, therefore leading to the absorption of VIS by photosensitizers (49). Finally, the cytotoxic reactive oxygen species (ROS) produced by the photosensitizers would attack the unwanted cells (Fig. 6) $(7,49)$. These results point to the significance of upconversion nanoparticles in non-invasive deep tissue imaging, drug delivery and photomodynamics $(50,51)$.

Qian et al (52) and Chatterjee and Yong (53) explored the effect of upconversion nanoparticles on PDT. Qian et al (52) proved that the effect of two photosensitizers in combination produced better than that of the use of a signal one. Noticeably, the combined photosensitizers did not need the excitation of multiple wavelengths. In the two studies (Fig. 7), multiple upconversion nanomaterials (UCNs) with different colors and emissions were irradiated under a 980-nm laser to activate two types of photosensitizers, and therefore the effect of PDT was improved. Upconversion nanoparticles effectively converted the near-infrared light into visible light emission (53). The wavelength of emitted visible light is matched with the maximum absorption wavelength of the photosensitizer, therefore activating the photosensitizer so as to produce the cytotoxic single line oxygen.

Mesoporous silica-coated upconversion nanoparticles with photosensitizers were loaded in B16-F0 melanoma-bearing C57BL/6 mice (54). The tumor grow th of the mice was examined under laser irradiation. Data from this study showed that the 
A

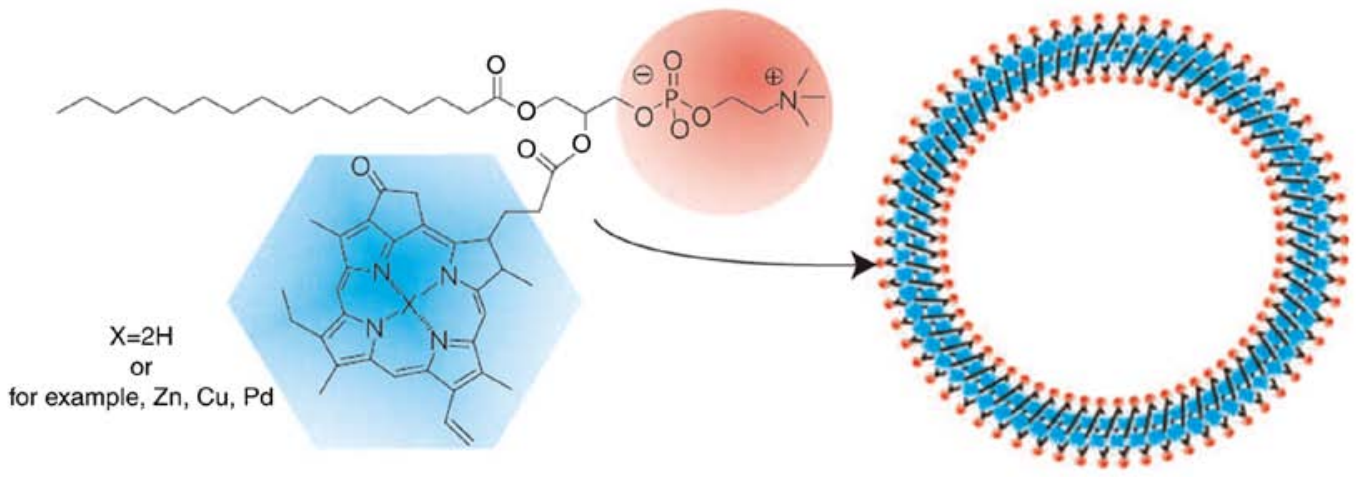

B
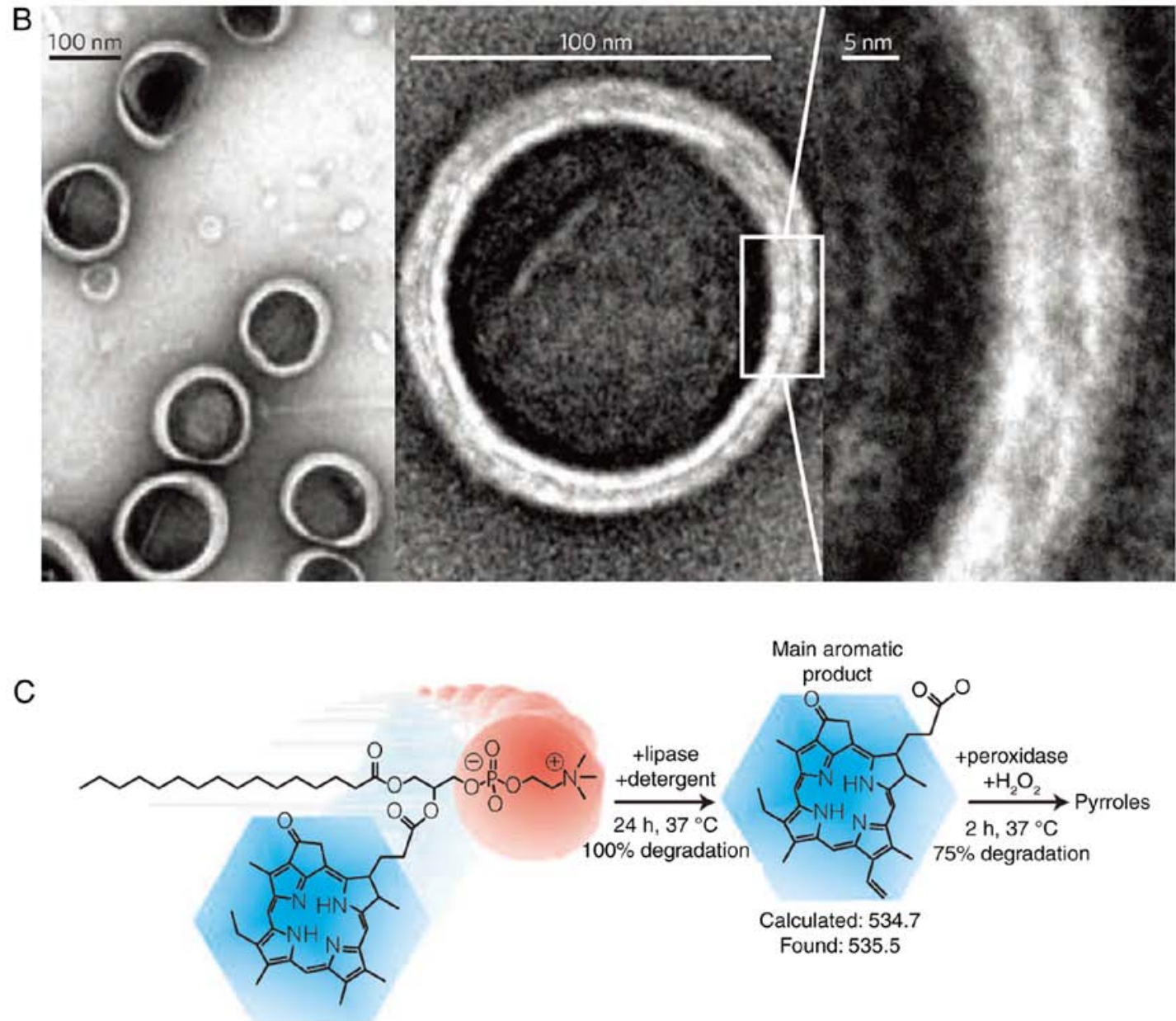

Figure 8. (A) The self-assembling mechanism of porphysomes. (B) Scanning electron microscopy (SEM) images of porphysomes. (C) The intracellular degradation mechanisms of the porphysome (Reprinted from ref 75 with permission. Copyright 2011, Springer Nature).

exposure of upconversion nanoparticles with $980-\mathrm{nm}$ laser irradiation activated MC540 and ZnPc, which then enhanced the therapy effect of PDT. Moreover, upconversion nanoparticle modification by folic acid and PEG (FA-PEG-UCNs) has also been developed to increase the bio-application values. Furthermore, upconversion nanoparticles could be conjugated with multiple dopants and employed for target labeling and imaging (55). A previous study demonstrated that FA-coupled up-converting nanophosphors (UCNPs) effectively targeted folate-receptor over-expressing HeLa cells in vitro and HeLa tumors in vivo (56). Recently, upconversion nanoparticles have been coupled with fluorescence resonant energy transfer
(FRET) technology to form efficient biological labels that were used for the diagnostics of diseases (55). In this study, 7-nm gold nanoparticles, which were coupled with the UC Na $\left(\mathrm{Y}_{1.5} \mathrm{Na}_{0.5}\right)$ $\mathrm{F}_{6}: \mathrm{Yb}^{3+}, \mathrm{Er}^{3+}$ nanoparticles (energy donors), were formed into a FRET biosensor whose strong absorption of gold nanoparticles matches well with the upconversion emission. This suggested that the efficiency of the FRET system based upon upconversion nanoparticles was elevated. Such a finding will promote the progression of fluorescence imaging. In addition, $\mathrm{Gd}^{3+}$-based upconversion nanoparticles have been formulated as magnetic resonance imaging (MRI) imaging agents. $\mathrm{NaGd}_{4}: \mathrm{Yb} / \mathrm{Er}$ nanoparticles may be used as probes for bioimaging $(57,58)$. 

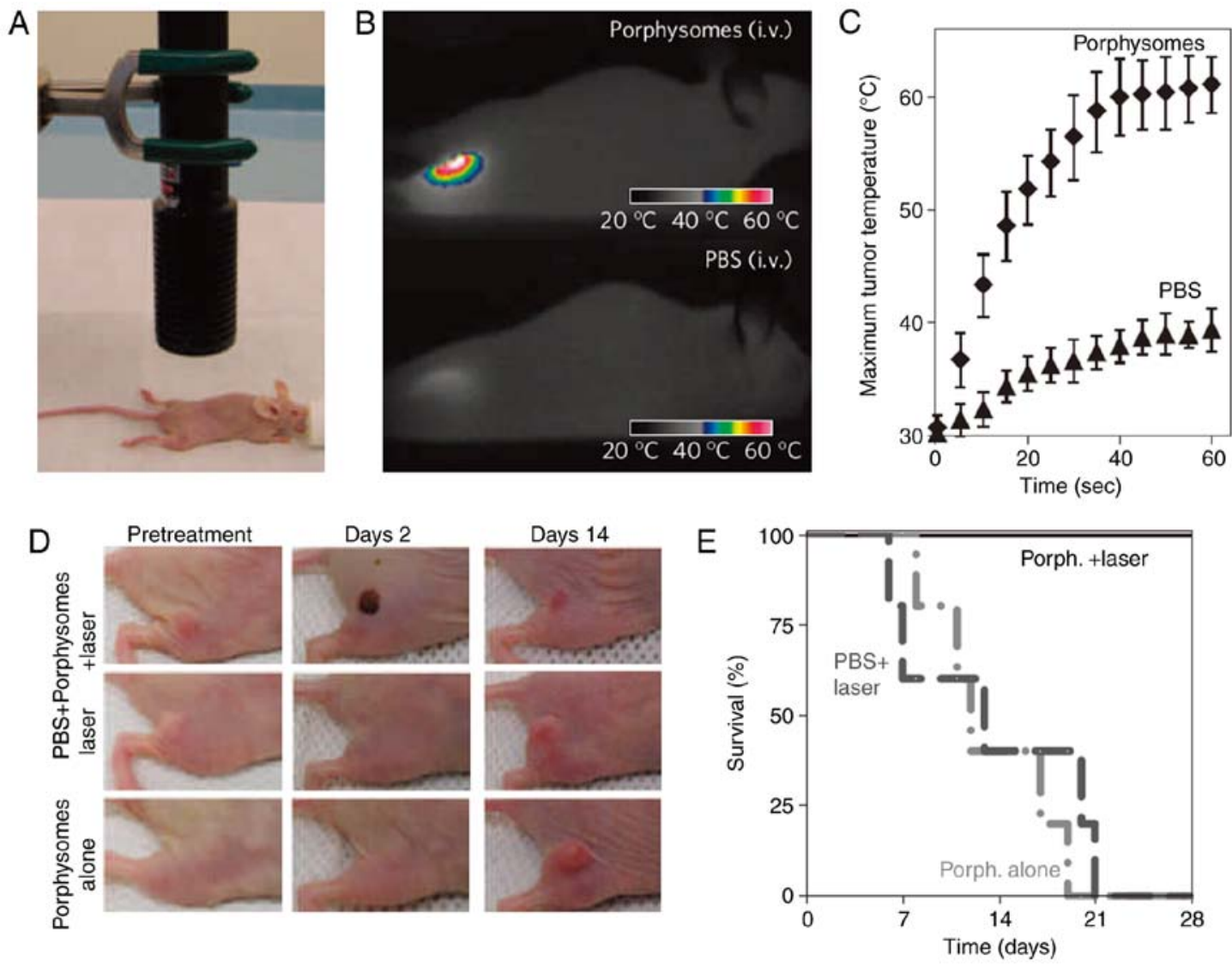

Figure 9. The application of porphysomes in the treatment of tumor-bearing mice. (A and B) Thermal images of mice-bearing tumor xenografts after being intravenously administered porphysomes or PBS and irradiated with a laser for photothermal therapy (PTT). (C) Quantification of increase in temperature in mice from A. (D) Resulting tumor response after PTT treatment at day 2 and 14. (E) Survival curve of mice receiving PTT (Reprinted from ref 75 with permission. Copyright 2011, Springer Nature).

Taken together, upconversion nanoparticles, which can convert near-infrared light to visible light in deep tissues, are promising in translating basic research concepts into clinical practice (59).

\section{Combination of PTT and PDT}

Supramolecular polymers. Supramolecular polymers display great potentials for applications in the biomedical field for its special structural and physicochemical properties $(60,61)$. The application of PDT was restricted for its oxygen-dependent characteristics (62). Porphyrins belong to the class of four-pyrrole, which is a major component of hemoglobin and myoglobin (63). The biological activity of porphyrins is indispensable to living organisms. These molecules are highly conjugated macrocyclic compounds and may contain a central metallic atom such as $\mathrm{Mg}^{2+}$ or $\mathrm{Fe}^{2+}$ (64). Porphyrins is considered as long-wavelength-absorbing sensitizers (65). Therefore, for its application in medical treatment $(66,67)$, porphyrins have generated scientific interest worldwide. Differences between the distribution and photodegradation of hematoporphyrin can be used to distinguish noncancerous from cancerous human breast tissue in Raman spectroscopy (68).

Porphysomes are similar to liposomes. The potential applications of this material have been discussed (69). According to previous studies, porphysomes could be formulated by exploiting the mechanism of hydrophobic self-assembly (Fig. 8A) (70-72). Zheng et al (73) found

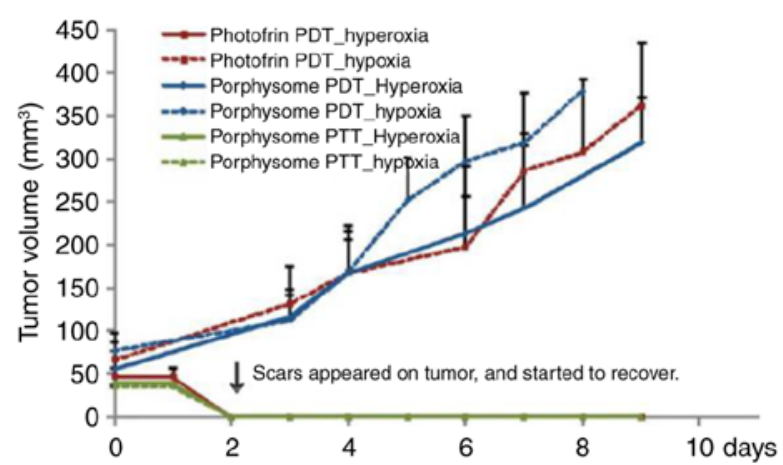

Figure 10. The tumor volume at different periods of time in hypoxia/hyperoxia tumor tissues treated with porphyrins and porphysomes (Reprinted from ref 75 with permission. Copyright 2013, American Chemical Society). PTT, photothermal therapy; PDT, photodynamic therapy (PDT).

that porphysomes, whose monodisperse diameter is $100 \mathrm{~nm}$ (Fig. 8B), could enhance its passive accumulation in tumor tissues through the osmotic cycle effect. Moreover, smaller nanoparticles with $30 \mathrm{~nm}$ diameter can be obtained by ultrasonic treatment in water. In addition, porphysomes with a diameter of $100 \mathrm{~nm}$ can be loaded with approximately $8 \times 10^{4}$ porphyrin molecules. Furthermore, porphysomes can be degraded in living cells (Fig. 8C). The fluorescence quenching test was performed to test the quenching property of porphysomes loaded with numerous porphyrin molecules in 
the same study (Fig. 9). The results showed that the quenching of porphysomes increased 1,200 times in comparison to the standard liposomes, generating a considerably stronger quenching than the common porphyrins. The fluorescence quenching could lead to the generation of heat and singlet oxygen production (69). Researchers suggested that porphysomes have a high photothermal conversion efficiency. It was also confirmed that porphysomes accumulated in tumors induced photothermal tumor ablation under laser irradiation (74). In addition, based on the tissue section and blood indicators, it can be observed that large doses of porphyrins did not cause liver and kidney injuries (74), and that porphysomes were prone to enzymatic degradation (74). Therefore, porphyrins may be used as a biodegradable, ultra-molecular photothermal therapy agents on account of their minimal toxicity and high photothermal conversion efficiency.

The effect of porphyrins and porphysomes in hypoxic/hyperoxic tumor tissues has previously been investigated. Huynh and Zheng pointed out that porphyrins exhibited acceptable performance in the treatment of hyperoxic tumors (69). This finding is consistent with the mechanism of single line oxygen in PDT. Interestingly, porphysomes exhibited excellent effects both in the treatment of hyperoxic tumors and in the treatment of hypoxic tumors, and effectively compensated for the defects in PDT (Fig. 10). This result may inspire research associated with ultra-molecular assembly in PDT, which may promote the quenching of the materials and produce more heat to kill cancer cells.

\section{Conclusions}

As non-invasive methods of phototherapy, the clinical value of photothermal therapy (PTT) and photodynamic therapy (PDT) are of significance in the prevention of cancer. Photothermal materials (such as precious metal nanomaterials, transition metal sulfide, carbon nanomaterials and upconversion nanoparticles) and photodynamic materials (such as phthalocyanas, porphyrins and other dye molecules) have been extensively investigated in recent years. The effect of PTT and PDT are largely dependent on distinct materials, different preparation methods, morphologies and modification methods. These parameters of materials can be modified in terms of varied purposes and needs. Additionally, PTT and PDT have their own advantages and defects. However, the combination of PTT and PDT not only provides enough time to achieve an effective treatment temperature for PTT, but also overcomes the obstacle of oxygen dependence accompanied with PDT. Therefore, such an combination could achieve a complementary synergistic effect in cancer therapy. Thus, a natural progression of this work is to practically transform the combination of PTT and PDT from basic science to clinical application.

\section{Acknowledgements}

The authors express thanks for permission to reprint the figures from the relevant publication organizations. The permission and copyright are stated in the figure legends and proper documentation has been provided.

\section{Funding}

This study was supported by the National Natural Science Foundation of China (grant nos. 81701894 and 81401583), the Major Projects Foundation of General Logistics Department of PLA (grant no. CNJ14L002), the Social Development Projects of Jiangsu Province (grant no. BE2017720), the Jiangsu Provincial Medical Youth Talent (grant nos. QNRC2016908, QNRC2016909) and the Peking Union Farsighted Emergency Project (grant no. RE2016-002), the Startup Fund of Wenzhou Institute of Biomaterials and Engineering (grant no. WIBEZD2017001-03).

\section{Availability of data and materials}

The datasets used and/or analyzed during the current study are available from the corresponding author on reasonable request.

\section{Authors' contributions}

ZY conceived and designed the review, and drafted and revised the manuscript. $\mathrm{ZS}$ analyzed the previous research, and drafted and revised the review. YR and XC contributed to the literature search, data collection, and revisions. WZ, $\mathrm{XZ}, \mathrm{ZM}$ and JS analyzed the previous research, and ZM and JS also revised the manuscript. SN designed and revised the review, and analyzed the previous research.

\section{Ethics approval and consent to participate}

Not applicable.

\section{Patient consent for publication}

Not applicable.

\section{Competing interests}

The authors state that they have no competing interests.

\section{References}

1. Oh J, Yoon H and Park JH: Nanoparticle platforms for combined photothermal and photodynamic therapy. Biomed Eng Lett 3: 67-73, 2013

2. Cao J, An H, Huang X, Fu G, Zhuang R, Zhu L, Xie J and Zhang F: Monitoring of the tumor response to nano-graphene oxide-mediated photothermal/photodynamic therapy by diffusion-weighted and BOLD MRI. Nanoscale 8: 10152-10159, 2016.

3. Lin J, Wang S, Huang P, Wang Z, Chen S, Niu G, Li W, He J, Cui D, Lu G, et al: Photosensitizer-loaded gold vesicles with strong plasmonic coupling effect for imaging-guided photothermal/photodynamic therapy. ACS Nano 7: 5320-5329, 2013.

4. Xiong LQ, Chen ZG, Yu MX, Li FY, Liu C and Huang CH: Synthesis, characterization, and in vivo targeted imaging of amine-functionalized rare-earth up-converting nanophosphors. Biomaterials 30: 5592-5600, 2009.

5. Shibu ES, Hamada M, Murase N and Biju V: Nanomaterials formulations for photothermal and photodynamic therapy of cancer. J Photochem Photobiol C: Photochem Rev 15: 53-72, 2013.

6. Liu J, Han J, Kang Z, Golamaully R, Xu N, Li H and Han X: In vivo near-infrared photothermal therapy and computed tomography imaging of cancer cells using novel tungsten-based theranostic probe. Nanoscale 6: 5770-5776, 2014. 
7. Wang C, Tao H, Cheng L and Liu Z: Near-infrared light induced in vivo photodynamic therapy of cancer based on upconversion nanoparticles. Biomaterials 32: 6145-6154, 2011.

8. Dolmans DE, Fukumura D and Jain RK: Photodynamic therapy for cancer. Nat Rev Cancer 3: 380-387, 2003.

9. Wen J, Xu Y, Li H, Lu A and Sun S: Recent applications of carbon nanomaterials in fluorescence biosensing and bioimaging. Chem Commun (Camb) 51: 11346-11358, 2015.

10. Lu X, Ji C, Jin T and Fan X: The effects of size and surface modification of amorphous silica particles on biodistribution and liver metabolism in mice. Nanotechnology 26: 175101, 2015.

11. Luo M, Shen C, Feltis BN, Martin LL, Hughes AE, Wright PF and Turney TW: Reducing $\mathrm{ZnO}$ nanoparticle cytotoxicity by surface modification. Nanoscale 6: 5791-5798, 2014

12. Chow EK and Ho D: Cancer nanomedicine: From drug delivery to imaging. Sci Transl Med 5: 216rv4, 2013.

13. Jaque D, Martinez Maestro L, del Rosal B, Haro-Gonzalez P, Benayas A, Plaza JL, Martin Rodriguez E and García Solé J: Nanoparticles for photothermal therapies. Nanoscale 6 : 9494-9530, 2014.

14. Thakor AS, Jokerst J, Zavaleta C, Massoud TF and Gambhir SS Gold nanoparticles: A revival in precious metal administration to patients. Nano Lett 11: 4029-4036, 2011.

15. Bazán-Díaz L, Mendoza-Cruz R, Velázquez-Salazar JJ, Plascencia-Villa G, Romeu D, Reyes-Gasga J, Herrera-Becerra R, José-Yacamán M and Guisbiers G: Gold-copper nanostars as photo-thermal agents: Synthesis and advanced electron microscopy characterization. Nanoscale 7: 20734-20742, 2015.

16. Pissuwan D and Niidome T: Polyelectrolyte-coated gold nanorods and their biomedical applications. Nanoscale 7: 59-65, 2015.

17. Wang Y, Liu Y, Luehmann H, Xia X, Brown P, Jarreau C, Welch $\mathrm{M}$ and Xia Y: Evaluating the pharmacokinetics and in vivo cancer targeting capability of Au nanocages by positron emission tomography imaging. ACS Nano 6: 5880-5888, 2012.

18. Wang Y, Black KC, Luehmann H, Li W, Zhang Y, Cai X, Wan D, Liu SY, Li M, Kim P, et al: Comparison study of gold nanohexapods, nanorods, and nanocages for photothermal cancer treatment. ACS Nano 7: 2068-2077, 2013.

19. Shrestha R, Elsabahy M, Luehmann H, Samarajeewa $S$ Florez-Malaver S, Lee NS, Welch MJ, Liu Y and Wooley KL: Hierarchically assembled theranostic nanostructures for siRNA delivery and imaging applications. J Am Chem Soc 134: 17362-17365, 2012.

20. Hasan W, Stender CL, Min HL, Nehl CL and Lee J: Tailoring the structure of nanopyramids for optimal heat generation. Nano Lett 9: 1555-1558, 2009

21. Kim DY, Yu T, Cho EC, Ma Y, Park OO and Xia Y: Synthesis of gold nano-hexapods with controllable arm lengths and their tunable optical properties. Angew Chem Int Ed Engl 50: 6328-6331, 2011

22. Kumar A and Liang XJ: Gold nanomaterials as prospective metal-based delivery systems for cancer treatment. In: Kretsinger RH, Uversky VN, Permyakov EA (eds) Encyclopedia of Metalloproteins. Springer, New York, NY, pp875-887, 2013.

23. Wu H, Yang R, Song B, Han Q, Li J, Zhang Y, Fang Y, Tenne R and Wang C: Biocompatible inorganic fullerene-like molybdenum disulfide nanoparticles produced by pulsed laser ablation in water. ACS Nano 5: 1276-1281, 2011.

24. Liu T, Wang C, Gu X, Gong H, Cheng L, Shi X, Feng L, Sun B and Liu Z: Drug delivery with PEGylated MoS2 nano-sheets for combined photothermal and chemotherapy of cancer. Adv Mater 26: 3433-3440, 2014

25. Lin H, Shan X, Hao L, Feng Q and Zhang Z: Copper sulfide nanoparticle-based localized drug delivery system as an effective cancer synergistic treatment and theranostic platform. Acta Biomate 54: 307-320, 2017.

26. Hessel CM, Pattani VP, Rasch M, Panthani MG, Koo B, Tunnell JW and Korgel BA: Copper selenide nanocrystals for photothermal therapy. Nano Lett 11: 2560-2566, 2011

27. Zhou Z, Kong B, Yu C, Shi X, Wang M, Liu W, Sun Y, Zhang Y, Yang $\mathrm{H}$ and Yang S: Tungsten oxide nanorods: an efficient nanoplatform for tumor CT imaging and photothermal therapy. Sci Rep 4: 3653, 2014.

28. Chen Z, Wang Q, Wang H, Zhang L, Song G, Song L, Hu J, Wang H, Liu J, Zhu M and Zhao D: Ultrathin PEGylated W18O49 nanowires as a new $980 \mathrm{~nm}$-laser-driven photothermal agent for efficient ablation of cancer cells in vivo. Adv Mater 25: 2095-2100, 2013.
29. Song G, Shen J, Jiang F, Hu R, Li W, An L, Zou R, Chen Z, Qin $\mathrm{Z}$ and $\mathrm{Hu} \mathrm{J}$ : Hydrophilic molybdenum oxide nanomaterials with controlled morphology and strong plasmonic absorption for photothermal ablation of cancer cells. ACS Appl Mater Interfaces 6: 3915-3922, 2014.

30. Tian Q, Tang M, Sun Y, Zou R, Chen Z, Zhu M, Yang S, Wang J, Wang J and Hu J: Hydrophilic flower-like CuS superstructures as an efficient $980 \mathrm{~nm}$ laser-driven photothermal agent for ablation of cancer cells. Adv Mater 23: 3542-3547, 2011.

31. Tian Q, Jiang F, Zou R, Liu Q, Chen Z, Zhu M, Yang S, Wang J, Wang J and Hu J: Hydrophilic Cu9S5 nanocrystals: a photothermal agent with a $25.7 \%$ heat conversion efficiency for photothermal ablation of cancer cells in vivo. ACS Nano 5 : 9761-9771, 2011

32. Knowles KE, Hartstein KH, Kilburn TB, Marchioro A, Nelson HD, Whitham PJ and Gamelin DR: Luminescent colloidal semiconductor nanocrystals containing copper: Synthesis, photophysics, and applications. Chem Rev 116: 10820-10851, 2016.

33. Liang S, Xie Z, Wei Y, Cheng Z, Han Y and Lin J: DNA decorated $\mathrm{Cu}_{9} \mathrm{~S}_{5}$ nanoparticles as NIR light responsive drug carriers for tumor chemo-phototherapy. Dalton Trans 47: 7916-7924, 2018.

34. Stubenvoll M, Schäfer B, Mann K, Walter A and Zittel L: Photothermal absorption measurements for improved thermal stability of high-power laser optics. Journal 88851R, 2013.

35. Miokovic T, Schulze V, Löhe D and Vöhringer O: Influence of heating rate, cooling rate and numbers of pulses on the microstructure of AISI 4140 after short-time-hardening. Int J Mater Prod Technol 24, 2005.

36. Tian Q, Hu J, Zhu Y, Zou R, Chen Z, Yang S, Li R, Su Q, Han Y and Liu X: Sub-10 nm Fe3O4@Cu(2-x)S core-shell nanoparticles for dual-modal imaging and photothermal therapy. J Am Chem Soc 135: 8571-8577, 2013.

37. Murali VS, Wang R, Mikoryak CA, Pantano P and Draper RK: The impact of subcellular location on the near infrared-mediated thermal ablation of cells by targeted carbon nanotubes. Nanotechnology 27: 425102, 2016

38. Madani SY, Naderi N, Dissanayake O, Tan A and Seifalian AM: A new era of cancer treatment: Carbon nanotubes as drug delivery tools. Int J Nanomedicine 6: 2963-2979, 2011.

39. Robinson JT, Tabakman SM, Liang Y, Wang H, Casalongue HS, Vinh D and Dai H: Ultrasmall reduced graphene oxide with high near-infrared absorbance for photothermal therapy. J Am Chem Soc 133: 6825-6831, 2011.

40. Yang K, Wan J, Zhang S, Tian B, Zhang Y and Liu Z: The influence of surface chemistry and size of nanoscale graphene oxide on photothermal therapy of cancer using ultra-low laser power. Biomaterials 33: 2206-2214, 2012.

41. Guo Y, Xu H, Li Y, Wu F, Li Y, Bao Y, Yan X, Huang Z and Xu P: Hyaluronic acid and Arg-Gly-Asp peptide modified Graphene oxide with dual receptor-targeting function for cancer therapy. J Biomater Appl 32: 54-65, 2017.

42. Liu Z, Robinson JT, Sun X and Dai H: PEGylated nanographene oxide for delivery of water-insoluble cancer drugs. J Am Chem Soc 130: 10876-10877, 2008.

43. Kim H, Lee D, Kim J, Kim TI and Kim WJ: Photothermally triggered cytosolic drug delivery via endosome disruption using a functionalized reduced graphene oxide. ACS Nano 7: 6735-6746, 2013.

44. Hu Z, Oleinick N and Hamblin MR: Photodynamic therapy as an emerging treatment modality for cancer and non-cancer diseases. J Anal Bioanal Tech S1: e001, 2014.

45. Cui S, Yin D, Chen Y, Di Y, Chen H, Ma Y, Achilefu S and Gu Y: In vivo targeted deep-tissue photodynamic therapy based on near-infrared light triggered upconversion nanoconstruct. ACS Nano 7: 676-688, 2013.

46. Ali SM and Olivo M: Mechanisms of action of phenanthroperylenequinones in photodynamic therapy (review). Int J Oncol 22: 1181-1191, 2003

47. Ge X, Liu J and Sun L: Controlled optical characteristics of lanthanide doped upconversion nanoparticles for emerging applications. Dalton Trans 46: 16729-16737, 2017.

48. Li Y, Dong Y, Tuerxun·Aidilibike, Liu X, Guo J and Qin W: Growth phase diagram and upconversion luminescence properties of NaLuF4: Yb3+/Tm3+/Gd3+ nanocrystals. RSC Adv 7: 44531-44536, 2017.

49. Wang F, Banerjee D, Liu Y, Chen X and Liu X: Upconversion nanoparticles in biological labeling, imaging, and therapy. Analyst 135: 1839-1854, 2010. 
50. Jin S, Zhou L, Gu Z, Tian G, Yan L, Ren W, Yin W, Liu X, Zhang $X, H u Z$ and Zhao Y: A new near infrared photosensitizing nanoplatform containing blue-emitting up-conversion nanoparticles and hypocrellin A for photodynamic therapy of cancer cells. Nanoscale 5: 11910-11918, 2013.

51. Wei Y, Chen Q, Wu B, Zhou A and Xing D: High-sensitivity in vivo imaging for tumors using a spectral up-conversion nanoparticle NaYF4: $\mathrm{Yb} 3+, \mathrm{Er} 3+$ in cooperation with a microtubulin inhibitor. Nanoscale 4: 3901-3909, 2012.

52. Qian HS, Guo HC, Ho PC, Mahendran R and Zhang Y: Mesoporous-silica-coated up-conversion fluorescent nanoparticles for photodynamic therapy. Small 5: 2285-2290, 2009.

53. Chatterjee DK and Yong Z: Upconverting nanoparticles as nanotransducers for photodynamic therapy in cancer cells Nanomedicine (Lond) 3: 73-82, 2008.

54. Idris NM, Gnanasammandhan MK, Zhang J, Ho PC, Mahendran R and Zhang Y: In vivo photodynamic therapy using upconversion nanoparticles as remote-controlled nanotransducers. Nat Med 18: 1580-1585, 2012.

55. Wang L, Yan R, Huo Z, Wang L, Zeng J, Bao J, Wang X, Peng Q and Li Y: Fluorescence resonant energy transfer biosensor based on upconversion-luminescent nanoparticles. Angew Chem Int Ed Engl 44: 6054-6057, 2005.

56. Xiong LQ, Chen ZG, Yu MX, Li FY, Liu C and Huang $\mathrm{CH}$ Synthesis, characterization, and in vivo targeted imaging of amine-functionalized rare-earth up-converting nanophosphors. Biomaterials 30: 5592-600, 2009.

57. Zhou J, Sun Y, Du X, Xiong L, Hu H and Li F: Dual-modality in vivo imaging using rare-earth nanocrystals with near-infrared to near-infrared (NIR-to-NIR) upconversion luminescence and magnetic resonance properties. Biomaterials 31: 3287-3295, 2010.

58. Shen X, He F, Wu J, Xu GQ, Yao SQ and Xu QH: Enhanced two-photon singlet oxygen generation by photosensitizer-doped conjugated polymer nanoparticles. Langmuir 27: 1739-1744, 2011.

59. Wang Y, Yang G, Wang Y, Zhao Y, Jiang H, Han Y and Yang P Multiple imaging and excellent anticancer efficiency of an upconverting nanocarrier mediated by single near infrared light. Nanoscale 9: 4759-4769, 2017

60. Bakker MH, Lee CC, Meijer EW, Dankers PY and Albertazzi L: Multicomponent supramolecular polymers as a modular platform for intracellular delivery. ACS Nano 10: 1845-1852, 2016.

61. Dong R, Zhou Y, Huang X, Zhu X, Lu Y and Shen J: Functional supramolecular polymers for biomedical applications. Adv Mater 27: 498-526, 2015

62. Selvasekar CR, Birbeck N, McMillan T, Wainwright M and Walker SJ: Photodynamic therapy and the alimentary tract. Aliment Pharmacol Ther 15: 899-915, 2001.

63. Khorami HH: Preliminary study on porphyrin derivatives as transfection reagents for mammalian cell. Porphyrins-synthesis. Anim Cell Biotechnol, 2013.
64. Chen $\mathrm{M}$ and Scheer H: Extending the limits of natural photosynthesis and implications for technical light harvesting. J Porphyr Phthalocyanines 17: 1-15, 2013.

65. Stilts CE, Nelen MI, Hilmey DG, Davies SR, Gollnick SO, Oseroff AR, Gibson SL, Hilf R and Detty MR: Water-soluble, core-modified porphyrins as novel, longer-wavelength-absorbing sensitizers for photodynamic therapy. J Med Chem 43: 2403-2410, 2000.

66. Cui L, Lin Q, Jin CS, Jiang W, Huang H, Ding L, Muhanna N, Irish JC, Wang F, Chen J and Zheng G: A pegylation-free biomimetic porphyrin nanoplatform for personalized cancer theranostics. ACS Nano 9: 4484-4495, 2015.

67. Rossi F, Bedogni E, Bigi F, Rimoldi T, Cristofolini L, Pinelli S, Alinovi R, Negri M, Dhanabalan SC, Attolini G, et al: Porphyrin conjugated $\mathrm{SiC} / \mathrm{SiOx}$ nanowires for X-ray-excited photodynamic therapy. Sci Rep 5: 7606, 2015.

68. Brozek-Pluska B and Kopec M: Raman microspectroscopy of Hematoporphyrins. Imaging of the noncancerous and the cancerous human breast tissues with photosensitizers. Spectrochim Acta A Mol Biomol Spectrosc 169: 182-191, 2016.

69. Huynh E and Zheng G: Porphysome nanotechnology: A paradigm shift in lipid-based supramolecular structures. Nano Today 9: 212-222, 2014

70. Li H, Marotta DE, Kim S, Busch TM, Wileyto EP and Zheng G: High payload delivery of optical imaging and photodynamic therapy agents to tumors using phthalocyanine-reconstituted low-density lipoprotein nanoparticles. J Biomed Opt 10: 41203, 2005.

71. Stefflova K, Chen J, Marotta D, Li H and Zheng G: Photodynamic therapy agent with a built-in apoptosis sensor for evaluating its own therapeutic outcome in situ. J Med Chem 49: 3850-3856, 2006.

72. Zheng G, Chen J, Li H and Glickson JD: Rerouting lipoprotein nanoparticles to selected alternate receptors for the targeted delivery of cancer diagnostic and therapeutic agents. Proc Natl Acad Sci USA 102: 17757-17762, 2005.

73. Zheng G, Chen J, Stefflova K, Jarvi M, Li H and Wilson BC: Photodynamic molecular beacon as an activatable photosensitizer based on protease-controlled singlet oxygen quenching and activation. Proc Natl Acad Sci USA 104: 8989-8994, 2007.

74. Lovell JF, Jin CS, Huynh E, Jin H, Kim C, Rubinstein JL, Chan WC, Cao W, Wang LV and Zheng G: Porphysome nanovesicles generated by porphyrin bilayers for use as multimodal biophotonic contrast agents. Nat Mater 10: 324-332, 2011.

This work is licensed under a Creative Commons Attribution-NonCommercial-NoDerivatives 4.0 International (CC BY-NC-ND 4.0) License. 